\title{
Point-of-care handheld ophthalmic ultrasound in the diagnosis and evaluation of raised intracranial pressure and Terson syndrome: a description of two cases
}

\section{L'échographie ophtalmologique portable au chevet pour le diagnostic et l'évaluation d'une élévation de la pression intracrânienne et du syndrome de Terson : une description de deux cas}

\author{
Jennifer Palermo, MD • Michel Bojanowski, MD • Stéphan Langevin, MD • \\ André Y. Denault, MD, PhD (i)
}

Received: 15 July 2019/Revised: 11 September 2019/Accepted: 2 October 2019/Published online: 22 November 2019

(C) Canadian Anesthesiologists' Society 2019

\begin{abstract}
Background Ultrasound (US) examination of the eye can be used to detect and monitor elevated intracranial pressure (ICP) and its consequences. Elevated ICP is transmitted to the contiguous optic nerve and its sheath (dura mater), thus underlying the development of papilledema and a widened sheath diameter. The US measurement of the optic nerve sheath diameter (ONSD) has previously been validated to diagnose and monitor
\end{abstract}

Electronic supplementary material The online version of this article (https://doi.org/10.1007/s12630-019-01531-4) contains supplementary material, which is available to authorized users.

J. Palermo, MD

Department of Anesthesiology, Université de Montréal,

Montreal, QC, Canada

M. Bojanowski, MD

Department of Neurosurgery, Centre Hospitalier de l'Université de Montréal, Montreal, QC, Canada

S. Langevin, MD

Department of Anesthesiology and Division of Critical Care, Institut Universitaire de Cardiologie et de Pneumologie, Quebec, QC, Canada

\section{A. Y. Denault, MD, PhD ( $₫)$}

Division of Critical Care, Centre Hospitalier de l'Université de Montréal, Montreal, QC, Canada

e-mail: andre.denault@umontreal.ca

Department of Anesthesiology and Critical Care Division, Montreal Heart Institute, Université de Montréal, 5000 Belanger Street, Montreal, QC H1T 1C8, Canada raised ICP. The occurrence of vitreous hemorrhage in association with subarachnoid hemorrhage (SAH)-i.e., Terson syndrome-can also be easily diagnosed using ophthalmic US. Because of its relevance in anesthesia and critical care, we describe how to perform the technique illustrated by two cases.

Case presentations A 72-yr-old man with hydrocephalus secondary to a SAH developed raised ICP following the removal of an external ventricular drainage (EVD) system. Daily ONSD measurements using handheld US allowed us to diagnose and monitor the progression and resolution of the intracranial hypertension following the placement of a second EVD system. We also describe the steps used to obtain ONSD measurements during the ophthalmic US examination of a 53-yr-old woman who presented with a stage IV SAH with concomitant bilateral vitreous hemorrhages or Terson syndrome.

Conclusion Ophthalmic US using a handheld device to measure and monitor ONSD at the bedside is useful in diagnosing and monitoring the progression of intracranial hypertension following EVD removal in a patient with hydrocephalus secondary to SAH. Ophthalmic US can also be used to identify concomitant vitreous hemorrhage that is associated with a worse prognosis.

\section{Résumé}

Contexte L'examen échographique (EG) de l'oeil peut être utilisé pour dépister et surveiller une pression intracrânienne (PIC) élevée et ses conséquences. Une PIC élevée est transmise au nerf optique et à sa gaine 
(dure-mère), et cause l'apparition d'un adème papillaire et d'un diamètre agrandi de la gaine. La mesure par EG du diamètre de la gaine du nerf optique (DGNO) a précédemment été validée comme outil pour diagnostiquer et monitorer une PIC élevée. La survenue d'une hémorragie vitréenne en association à une hémorragie sous-arachnö̈dienne (HSA) - c'est-à-dire, le syndrome de Terson - peut également être aisément diagnostiquée à l'aide de l'échographie ophtalmologique. En raison de sa pertinence pour les soins anesthésiques et critiques, nous décrivons la façon de réaliser cette technique telle qu'illustrée par deux cas.

Présentations des cas Une PIC élevée est apparue chez un homme de 72 ans atteint d'hydrocéphalie secondaire à une HSA suite au retrait d'une dérivation ventriculaire externe (DVE). Des mesures quotidiennes du DGNO prises à l'aide d'un appareil portable d'échographie nous ont permis de diagnostiquer et monitorer la progression et la résolution de la pression intracrânienne suite à la mise en place d'une deuxième DVE. Nous décrivons également les étapes utilisées afin d'obtenir des mesures du DGNO pendant l'examen échographique ophtalmologique d'une femme de 53 ans avec une HSA de stade IV avec hémorragies vitréennes bilatérales concomitantes ou syndrome de Terson.

Conclusion L'échographie ophtalmologique à l'aide d'un dispositif portable utilisé pour mesurer et surveiller le DGNO au chevet peut servir à diagnostiquer et surveiller la progression d'une hypertension intracrânienne suite au retrait d'un dispositif de DVE chez un patient souffrant d'hydrocéphalie secondaire à une HSA. L'échographie ophtalmologique peut également être utilisée pour identifier une hémorragie vitréenne concomitante, une condition associée à de moins bons devenirs.

Point-of-care ultrasound (POCUS) is increasingly recognized as an integral part of the clinical exam. ${ }^{1}$ The widespread use of bedside ultrasound (US) has been facilitated by the availability of miniaturized handheld US devices. The clinical uses of POCUS are extensive, particularly in patients who may be difficult to interview and examine, such as patients with neurologic lesions. Patients with subarachnoid hemorrhage $(\mathrm{SAH})$ are at risk of hydrocephalus, which is a frequent cause of deterioration. While computed tomography (CT) scans are regularly performed to monitor for signs of intracranial hypertension (ICH) secondary to hydrocephalus, POCUS techniques may provide clinicians with a helpful and safe bedside diagnostic tool. Optic nerve sheath diameter (ONSD) obtained by US has been validated for the evaluation of ICH and can be used to monitor the progression of intracranial pressure. ${ }^{2-8}$ As a complication of $\mathrm{SAH}$, vitreous hemorrhage can also occur in such patients and is known as Terson syndrome. ${ }^{9-12}$ Its presence is associated with higher SAH grade and poorer outcome. ${ }^{10}$ The purpose of this report is to illustrate the ultrasonographic technique using a handheld twodimensional linear US probe for obtaining ONSD measurements. We describe examples of its use in one patient with hydrocephalus after $\mathrm{SAH}$ and in another patient with Terson syndrome. Consent for these reports was granted by the patients' families.

\section{Case 1}

A 72-yr-old man with multiple comorbidities presented with severe headache, nausea, vomiting, confusion, and memory loss three days after a fall. He was diagnosed with a Fischer grade-3 and World Federation of Neurological Surgeons grade-2 SAH secondary to a ruptured anterior communicating artery aneurysm. A right trans-frontal external ventricular drainage (EVD) system was inserted because of clinical and radiographic signs of $\mathrm{ICH}$ and hydrocephalus. He was taken to the interventional radiology suite for angio-embolization and stent placement that same day, which was complicated by multiple cerebral emboli. He was later transferred to the neurologic intensive care unit for further monitoring. The subsequent EVD weaning process was prolonged because of persistent hydrocephalus; it was eventually removed on the $15^{\text {th }}$ day of hospitalization. At that time, we performed daily POCUS measurements of ONSD using handheld US (Vscan GE Healthcare, NY, USA). The ONSD at baseline was $5.6 \mathrm{~mm}$ on hospital day 16, increased to $6.1 \mathrm{~mm}$ on day 17 , and finally to $6.9 \mathrm{~mm}$ on day 18 . The patient's clinical exam concomitantly deteriorated, as he became more somnolent and less engaged with his family members. On the basis of these findings, a CT scan was obtained and a second EVD was placed from a right posterior approach on day 18; elevated intracranial pressure (ICP) was confirmed during the EVD insertion by the neurosurgeon based on the unusual height of the cerebral-spinal jet upon insertion of the drain. The ONSD measurement on the day following the second EVD decreased to a baseline of $5.5 \mathrm{~mm}$ and corresponded to an improvement in the patient's clinical examination (Fig. 1). Similarly, a follow-up CT scan showed decreased (though persistently moderate grade) hydrocephalus and periventricular edema. We continued to monitor the ONSD daily, and the last measurement remained consistent with the baseline measurement, at 5.8 $\mathrm{mm}$ on day 22. Because of his persistent and severe 
Fig. 1 Optic nerve sheath measurements. Optic nerve sheath (ONS) in a 72-yr-old man with subarachnoid hemorrhage following removal of an external ventricular drain (EVD). A) Baseline ONS measurement at $5.6 \mathrm{~mm}$ taken from outer sheath to outer sheath, $3 \mathrm{~mm}$ orthogonal to the optic disc. B, C) Progression of the ONS measured at $6.9 \mathrm{~mm}$ and $5.5 \mathrm{~mm}$ before and after EVD placement, respectively.
A

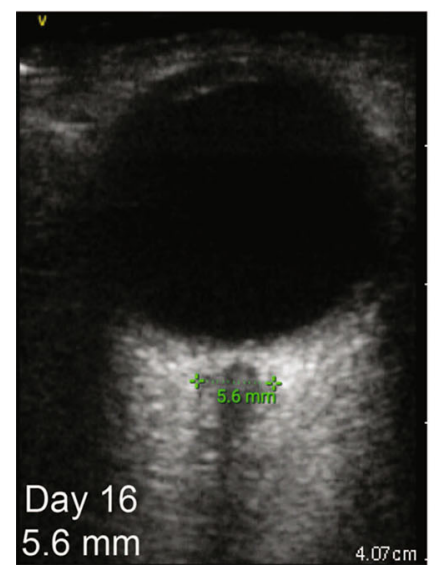

B

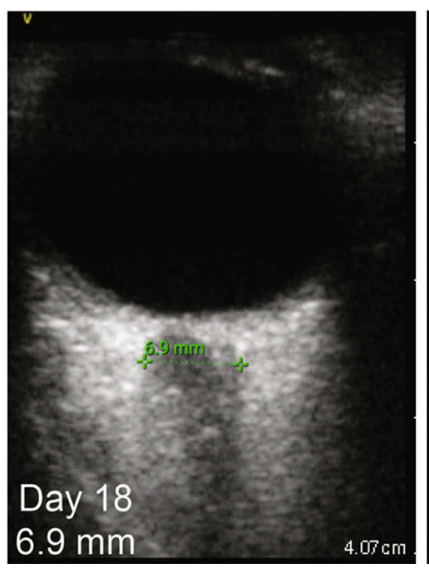

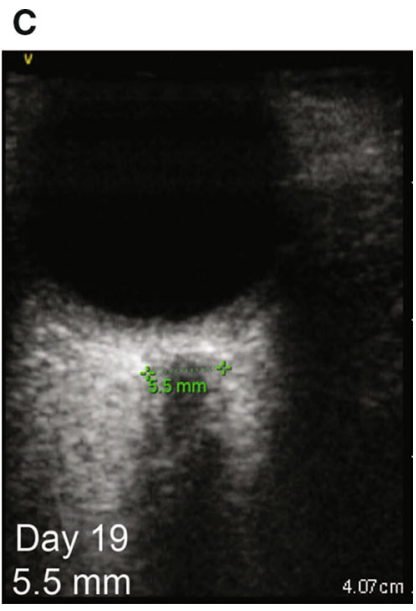

neurologic deficits, a decision was made by the family to limit the level of intervention for any eventual complication and he died on day 59 of hospitalization.

\section{Case 2}

A 53-yr-old woman with no prior medical history presented to a community hospital with an altered level of consciousness. She was subsequently transferred to our centre with a Fisher grade- 4 SAH with intra-parenchymal hemorrhage secondary to a left posterior communicating artery aneurysm. She underwent right frontal EVD placement upon arrival and was then taken to the neuroradiology suite for aneurysm embolization. Her hospital course was complicated by bi-frontal ischemia secondary to anterior communicating artery and middle cerebral artery vasospasm, which manifested itself clinically as a severe hemiparesis and expressive aphasia. Bilateral vitreous hemorrhages, which were not evident on CT scan, were found on POCUS ophthalmic examination (Fig. 2A, B) (videos 1-3, available as Electronic Supplementary Material). In addition, US was used to follow pupillary size and ONSD the latter being enlarged (Fig. 2C, D). After consultation with an ophthalmologist, it was felt that the bilateral vitreous hemorrhage most likely represented a Terson syndrome in the context of a grade- 4 SAH. She died suddenly on day 31 of hospitalization because of a suspected pulmonary embolism.

\section{Steps in measuring optic nerve sheath diameter using ultrasound}

Figure 3 illustrates the technique that we use to examine the eye; the ten steps are further detailed in the Table. To perform POCUS ONSD measurements using handheld US we start by selecting a high frequency US probe with software settings adjusted to the ocular or nerve preset function. We ensure that the thermal index is 0 and that the mechanical index is $<0.2$, as per United States Food and Drug Administration guidelines for ophthalmic US examination. ${ }^{13}$ We then adjust the US depth to between 4 and $5 \mathrm{~cm}$ and set the focus index at approx. $2.5 \mathrm{~cm}$. On the screen, we record the patient name, medical record number, and indicate which eye is being imaged. With the patient in supine position, the handheld US device is placed on the patient's forehead and the probe is gently placed on the patient's closed eyelid at the base of the brow, taking care not to apply any undue pressure on the globe (Fig. 3). Two different motions are made: tilting and sliding. First, the US probe is tilted anteriorly and posteriorly until the round ocular area is seen. Then the optic nerve and its sheath are visualized as a darker rectangular area. Second, we adjust the image by sliding medially or laterally to centre the optic nerve at the six o'clock position on the screen to see the longest portion of the optic nerve. The optic nerve sheath border should be clearly identified and symmetrical on both sides. The image is optimized by repeating the anterior-posterior tilting motion until the maximal ONSD is imaged. At this point, the "freeze" function on the US device machine is activated and the captured frames are reviewed to select the best one for measuring the ONSD. By convention, the optic nerve including its sheath is measured at a distance of 3 $\mathrm{mm}$ from the optic disc. It is recommended to repeat this measurement in triplicate to obtain a mean distance value. ${ }^{14-16}$ The learning curve for the ONSD technique is initially steep and generally plateaus around the $20^{\text {th }}$ exam. Similarly, inter-observer variation tends to decrease after 20 supervised exams. ${ }^{17,18}$ For the purpose of these cases, the US exams were performed by a novice having completed over 20 supervised ONSD exams and were 

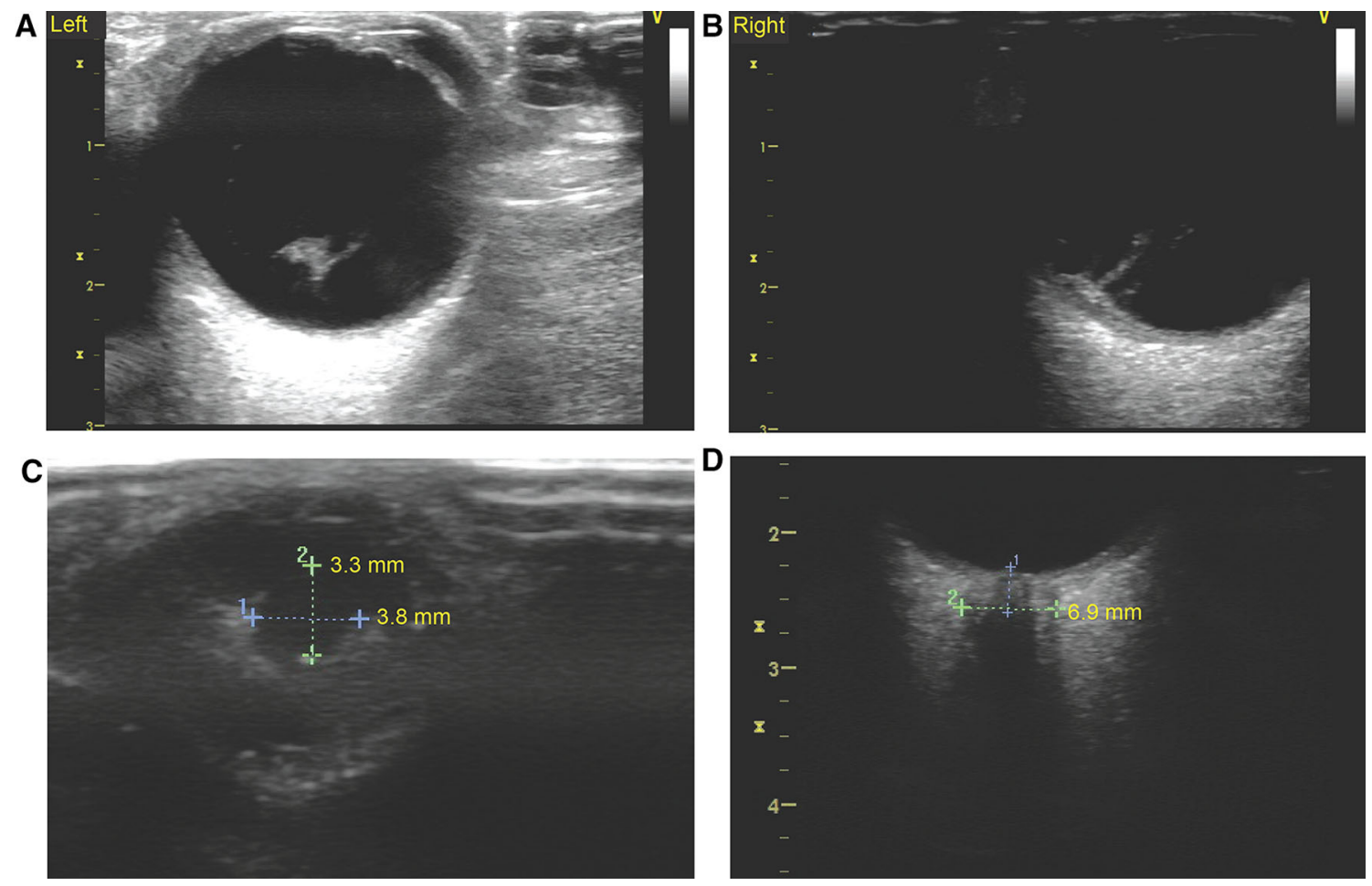

Fig. 2 Terson syndrome in a 53-yr-old woman with subarachnoid hemorrhage stage IV. The echodensities on the left (A) and on the right (B) eyes correspond to bilateral vitreous hemorrhage diagnosed

validated by an experienced ultrasonographer, with excellent correlation between both users.

\section{Discussion}

Hydrocephalus occurs in $20-30 \%$ of SAH cases and may lead to potentially devastating consequences. ${ }^{19}$ Although the pathophysiology is not clearly elucidated, cerebrospinal fluid (CSF) flow obstruction is most likely due to accumulation of blood clots or induced inflammation in the subarachnoid space preventing CSF absorption, with an onset that may vary between hours and weeks after SAH. ${ }^{19}$ There are presently no guidelines for the early diagnosis and management of hydrocephalus, despite the importance of effective and timely treatment to prevent the development of chronic symptomatic hydrocephalus. Reliance on clinical symptoms and interpretation of CT scans are crucial for the management of patients with SAH. Nevertheless, the clinical exam is often difficult in patients who are often heavily sedated (or comatose) and transport for serial CT scans can be logistically problematic in this critically ill population. Alternative imaging techniques such as US for ICP monitoring could be useful, particularly in pediatric or obstetrical populations where there is a heightened concern for undesirable radiation exposure. ${ }^{20,21}$ using ocular ultrasound. C) Pupillary dimensions can be easily obtained. D) Dilated optic nerve sheath of $6.9 \mathrm{~mm}$ (see videos 1-3).

The optic nerve and its sheath, which is formed by the dura mater, are contiguous with the brain and intracranial structures, explaining the formation of papilledema and widened ONSD in ICH. The optic nerve sheath (ONS) has sufficient elasticity to allow a measurable dilation in response to intracranial hypertension. ${ }^{22}$ Nevertheless, because of variable individual pressure-diameter relationships, it is difficult to predict subarachnoid pressure exactly by single time point scans. In a recent meta-analysis evaluating ONSD as an estimator of ICP, seven prospective studies $(n=320)$ using thresholds between $4.8 \mathrm{~mm}$ and $6.3 \mathrm{~mm}$ and a cutoff $\mathrm{ICP}>20 \mathrm{mmHg}$, a hierarchical summary receiver-operating characteristic curve was found to be $0.938 .^{23}$ Nevertheless, the pooled diagnostic odds ratio was 68.10 with a wide $95 \%$ confidence interval (26.8 to 144), suggesting that although it may be a good diagnostic tool, it should be used cautiously. ${ }^{23}$ In a recent systematic review and metaanalysis by Fernando et al. on the diagnosis of elevated intracranial pressure in critically ill adults, ${ }^{24}$ the authors report ten studies on ONSD with a pooled area under the receiver-operating curve of $0.94 \% \quad(95 \%$ confidence interval, 0.91 to $0.96, \mathrm{I}^{2}=60.9 \%$ ) for detection of elevated intracranial pressure using ONSD sonography.

Attention should also be paid to which ONSD cutoff is being used, as this can alter diagnostic performance of the 


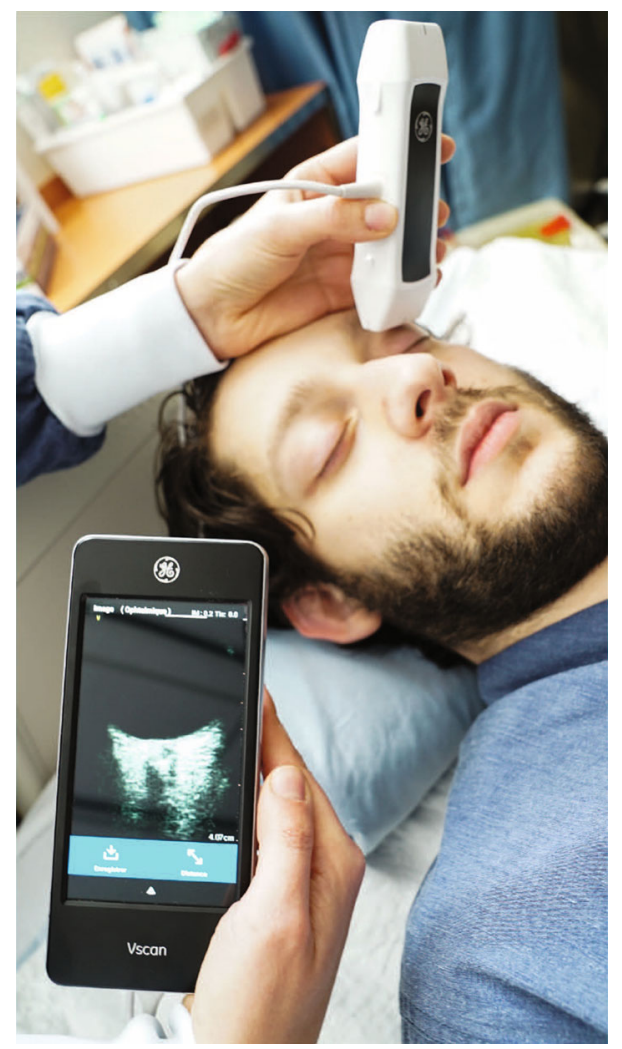

Fig. 3 Optic nerve sheath ultrasonography. Hand placement on a subject's forehead and gentle apposition of the linear probe on the subject's closed eyelid.

test. An ONSD of $5 \mathrm{~mm}$ is commonly used as a threshold above which patients exhibit either clinical or radiologic signs of elevated ICP. This value has been validated with ventriculostomy measurements of ICP. ${ }^{14}$

We argue that rather than making a decision on a single time point, it may be more useful to monitor ONSD progression. Wang evaluated the correlation between US measurement of ONSD and ICP at two time points in a study of 60 patients, and found that dynamic evaluation of ONSD was strongly correlated with the change in ICP. ${ }^{25}$ Combining ONS measurement with brain US and straight sinus venous systolic flow velocity is also a promising method in improving the sensitivity and specificity of the measurement. $^{26}$

Measuring ONSD by CT at the time of hospital admission for SAH has been shown to correlate with neurologic prognosis at six months. ${ }^{27}$ The combination of clinical grading scale score with ONSD by CT performed even better than the use of each marker alone. ${ }^{27}$ Rather or in addition to CT evaluation, POCUS ONSD measurement with a handheld US device as part of an integral clinical exam could potentially further simplify prognostication in patients with SAH. Similarly, Terson syndrome is an adverse prognostic feature in patients with $\mathrm{SAH}^{9-12,28}$ Although the pathogenesis of Terson syndrome remains unclear, it is relatively common occurring in approximately $13 \%$ of patients hospitalized for SAH. ${ }^{28}$ Recognition of this syndrome using US could further help clinicians stratify patients; however, caution must be used as distinguishing vitreous hemorrhage from other benign vitreous pathologies may be difficult for non-ophthalmologist users. Ultrasound does not replace an ophthalmological consultation and dilated ophthalmic exam to definitively diagnose vitreous hemorrhage in patients with SAH.

\section{Conclusion}

These two cases highlight the utility of bedside US ocular examination and ONSD measurement as a noninvasive tool for monitoring progression of ICH in patients whose clinical exams were difficult to interpret and where doing repeat serial CT scanning would be logistically difficult.

Table Ten-step approach to using ocular ultrasound

1) Select a high frequency ultrasound probe and set to the ocular or nerve preset function

2) Ensure the thermal index is 0 and that the mechanical index is $<0.2$

3) Adjust the depth between 4 and $5 \mathrm{~cm}$ and set the focus index around $2.5 \mathrm{~cm}$.

4) Record patient name, medical record number, and left or right eye.

5) Steadily rest hand on the patient's forehead and gently place the probe on the patient's closed eyelid at the base of the brow (Fig. 3).

6) Tilt the probe anteriorly and posteriorly in a 12 to 6 o'clock orientation until the optic nerve and his sheath are visualized. Analyze the pupillary dimension, posterior chamber for Terson syndrome and papilledema.

7) Slide the ultrasound beam to centre image so that the optic nerve sheath (ONS) is at 6 o'clock on the ultrasound image by sliding medially or laterally.

8) Freeze and select the best frame where easily delineated and symmetric ONS can be identified.

9) Measure the ONS diameter at a distance of $3 \mathrm{~mm}$ perpendicular to the optic disc.

10) Repeat this measure three times to obtain the mean value*.

*To improve the value of ONS measurement as an index of intracranial hypertension, brain ultrasound can be performed for midline shift evaluation, ventricular dimension, and arterial and venous Doppler velocities to complement the neurologic evaluation. ${ }^{30}$ 
We did not rely on single measurements, and rather followed the daily progression of ONSD. Handheld US techniques such as this one are gaining popularity among intensive care physicians for their accessibility, low-cost, and great safety profile. ${ }^{29}$ Larger-scale studies are needed to elucidate the role of bedside ONSD US in the clinical decision-making process for early management of $\mathrm{ICH}$.

Author contributions Jennifer Palermo contributed to all aspects of this manuscript, including study conception and design; acquisition, analysis, and interpretation of data; and drafting the article. Michel Bojanowski contributed to study conception and design as well as the interpretation of the data. Stéphan Langevin contributed to study conception and design. André $Y$. Denault contributed to all aspects of this manuscript, including study conception and design; acquisition, analysis, and interpretation of data; and drafting the article.

Conflicts of interest Dr. Denault is on the Speakers bureau for Masimo, Medtronic, and CAE Healthcare.

Funding statement Supported by the Richard I. Kaufman Endowment Fund in Anesthesia and Critical Care and the Montreal Heart Institute Foundation. The funding body had no role in the study design, in the collection, analysis, and interpretation of data, and in the writing of the manuscript.

Editorial responsibility This submission was handled by Dr. Philip M. Jones, Associate Editor, Canadian Journal of Anesthesia.

\section{References}

1. Narula J, Chandrashekhar Y, Braunwald E. Time to add a fifth pillar to bedside physical examination: inspection, palpation, percussion, auscultation, and insonation. JAMA Cardiol 2018; 3 : 346-50.

2. Salgarello T, Tamburrelli C, Falsini B, Giudiceandrea A, Colotto $A$. Optic nerve diameters and perimetric thresholds in idiopathic intracranial hypertension. Br J Ophthalmol 1996; 80: 509-14.

3. Tamburrelli C, Salgarello T, Caputo CG, Giudiceandrea A, Scullica L. Ultrasonographic evaluation of optic disc swelling: comparison with CSLO in idiopathic intracranial hypertension. Invest Ophthalmol Vis Sci 2000; 41: 2960-6.

4. Girisgin AS, Kalkan E, Kocak S, Cander B, Gul M, Semiz M. The role of optic nerve ultrasonography in the diagnosis of elevated intracranial pressure. Emerg Med J 2007; 24: 251-4.

5. Geeraerts $T$, Launey $Y$, Martin L, et al. Ultrasonography of the optic nerve sheath may be useful for detecting raised intracranial pressure after severe brain injury. Intensive Care Med 2007; 33: 1704-11.

6. Geeraerts T, Merceron S, Benhamou D, Vigue B, Duranteau J. Non-invasive assessment of intracranial pressure using ocular sonography in neurocritical care patients. Intensive Care Med 2008; 34: 2062-7.

7. Goel RS, Goyal NK, Dharap SB, Kumar M, Gore MA. Utility of optic nerve ultrasonography in head injury. Injury 2008; 39: 51924.

8. Maissan IM, Dirven PJ, Haitsma IK, Hoeks SE, Gommers D, Stolker RJ. Ultrasonographic measured optic nerve sheath diameter as an accurate and quick monitor for changes in intracranial pressure. J Neurosurg 2015; 123: 743-7.

9. Roux FX, Panthier JN, Tanghe YM, et al. Terson's syndrome and intraocular complications in meningeal hemorrhages (26 cases) (French). Neurochirurgie 1991; 37: 106-10.

10. Seif GI, Teichman JC, Reddy K, Martin C, Rodriguez AR. Incidence, morbidity, and mortality of Terson syndrome in Hamilton. Ontario. Can J Neurol Sci 2014; 41: 572-6.

11. Bauerle J, Gross NJ, Egger K, et al. Terson's syndrome: diagnostic comparison of ocular sonography and CT. J Neuroimaging 2016; 26: 247-52.

12. Ren $Y, W u Y$, Guo $G$. Terson syndrome secondary to subarachnoid hemorrhage: a case report and literature review. World Neurosurg 2018; DOI: https://doi.org/10.1016/j.wneu. 2018.12.084.

13. Palte HD, Gayer S, Arrieta E, et al. Are ultrasound-guided ophthalmic blocks injurious to the eye? A comparative rabbit model study of two ultrasound devices evaluating intraorbital thermal and structural changes. Anesth Analg 2012; 115: 194201.

14. Kimberly HH, Shah $S$, Marill K, Noble V. Correlation of optic nerve sheath diameter with direct measurement of intracranial pressure. Acad Emerg Med 2008; 15: 201-4.

15. Rajajee V, Vanaman M, Fletcher JJ, Jacobs TL. Optic nerve ultrasound for the detection of raised intracranial pressure. Neurocrit Care 2011; 15: 506-15.

16. del Saz-Saucedo P, Redondo-Gonzalez O, Mateu-Mateu A, Huertas-Arroyo $R, \quad$ Garcia-Ruiz $R$, Botia-Paniagua $E$. Sonographic assessment of the optic nerve sheath diameter in the diagnosis of idiopathic intracranial hypertension. J Neurol Sci 2016; 361: 122-7.

17. Zeiler FA, Ziesmann MT, Goeres $P$, et al. A unique method for estimating the reliability learning curve of optic nerve sheath diameter ultrasound measurement. Critical Ultrasound J 2016; DOI: https://doi.org/10.1186/s13089-016-0044-X.

18. Shrestha GS, Upadhyay B, Shahi A, Jaya Ram KC, Joshi P, Poudyal BS. Sonographic measurement of optic nerve sheath diameter: how steep is the learning curve for a novice operator? Indian J Crit Care Med 2018; 22: 646-9.

19. Germanwala AV, Huang J, Tamargo RJ. Hydrocephalus after aneurysmal subarachnoid hemorrhage. Neurosurg Clin N Am 2010; 21: 263-70.

20. Dubost C, Le Gouez A, Jouffroy V, et al. Optic nerve sheath diameter used as ultrasonographic assessment of the incidence of raised intracranial pressure in preeclampsia: a pilot study. Anesthesiology 2012; 116: 1066-71.

21. Dahlmann-Noor AH, Adams GW, Daniel MC, et al. Detecting optic nerve head swelling on ultrasound and optical coherence tomography in children and young people: an observational study. Br J Ophthalmol 2018; 102: 318-22.

22. Hansen HC, Helmke $K$. Validation of the optic nerve sheath response to changing cerebrospinal fluid pressure: ultrasound findings during intrathecal infusion tests. J Neurosurg 1997; 87: 34-40.

23. Robba $C$, Santori $G$, Czosnyka $M$, et al. Optic nerve sheath diameter measured sonographically as non-invasive estimator of intracranial pressure: a systematic review and meta-analysis. Intensive Care Med 2018; 44: 1284-94.

24. Fernando SM, Tran A, Cheng W, et al. Diagnosis of elevated intracranial pressure in critically ill adults: systematic review and meta-analysis. BMJ 2019; DOI: https://doi.org/10.1136/bmj. 14225.

25. Wang $L J$, Chen $L M$, Chen $Y$, et al. Ultrasonography assessments of optic nerve sheath diameter as a noninvasive and dynamic method of detecting changes in intracranial pressure. JAMA Ophthalmol 2018; 136: 250-6. 
26. Robba C, Cardim D, Tajsic T, et al. Ultrasound non-invasive measurement of intracranial pressure in neurointensive care: a prospective observational study. PLoS Med 2017; DOI: https:// doi.org/10.1371/journal.pmed.1002356.

27. Lee S, Kim YO, Baek JS, Ryu JA. The prognostic value of optic nerve sheath diameter in patients with subarachnoid hemorrhage. Crit Care 2019; DOI: https://doi.org/10.1186/s13054-019-2360-6.

28. McCarron MO, Alberts MJ, McCarron P. A systematic review of Terson's syndrome: frequency and prognosis after subarachnoid haemorrhage. J Neurol Neurosurg Psychiatry 2004; 75: 491-3.
29. Bryson GL, Grocott HP. Point-of-care ultrasound: a protean opportunity for perioperative care. Can J Anesth 2018; 65: 341-4.

30. Robba C, Goffi A, Geeraerts T, et al. Brain ultrasonography: methodology, basic and advanced principles and clinical applications. A narrative review. Intensive Care Med 2019; 45: 913-27.

Publisher's Note Springer Nature remains neutral with regard to jurisdictional claims in published maps and institutional affiliations. 